\title{
The Adaptation Needs of International Social Work Students: A Proposed Mentoring Approach
}

\author{
Hyun-a Song \\ University of Pittsburgh \\ Helen E. Petracchi \\ University of Pittsburgh
}

\begin{abstract}
Given the increasing numbers of international social work students in the United States, it is incumbent upon social work faculty to understand their needs for appropriate support as they adjust to life as foreign-born students. This paper has two main goals. First, we discuss contributions and challenges faced by international social work students. Second, as a form of support, we propose a mentoring approach pairing retired social work professionals with international social work students and argue that this may provide a mutually beneficial experience for both. That is, this study identifies adaptation needs specific to international social work students, describes the proposed paired-mentoring approach, and discusses implications of this approach.
\end{abstract}

Keywords: international social work students, mentoring approach, retired social workers

\section{Introduction}

Rapid globalization has increased the number of international students enrolled in higher education in the United States, with more than 186 American universities now educating international students (Institute of International Education, 2010). During the 2013-2014 academic year, there were 886,052 international students in American colleges and universities, representing an 8.1\% increase over the previous academic year (Institute of International Education, 2014). While in school, international students contribute approximately $\$ 27$ billion annually to the United States' economy through their tuition and living expenses, making higher education the nation's fifth largest service export (Institution of International Education, 2014). In social work, the number of international students has increased as well. According to the Council on Social Work Education (CSWE), the number of full-time international students in accredited bachelor of social work programs in the United States increased over three times (221\%) between 2006 and 2013, from 127 to 408. During this same time period, accredited master of social work (MSW) programs increased their enrollment of full-time international students by $116 \%$ from 320 to 694 ; doctoral programs in social work reported a $60 \%$ increase in international students from 205 to 328 (CSWE, 2013; Rai, 2002; see Figure 1). Hence, more than 2,000 full-time/part-time international social work students enrolled in U.S. colleges and universities in 2013 alone (CSWE, 2013). 


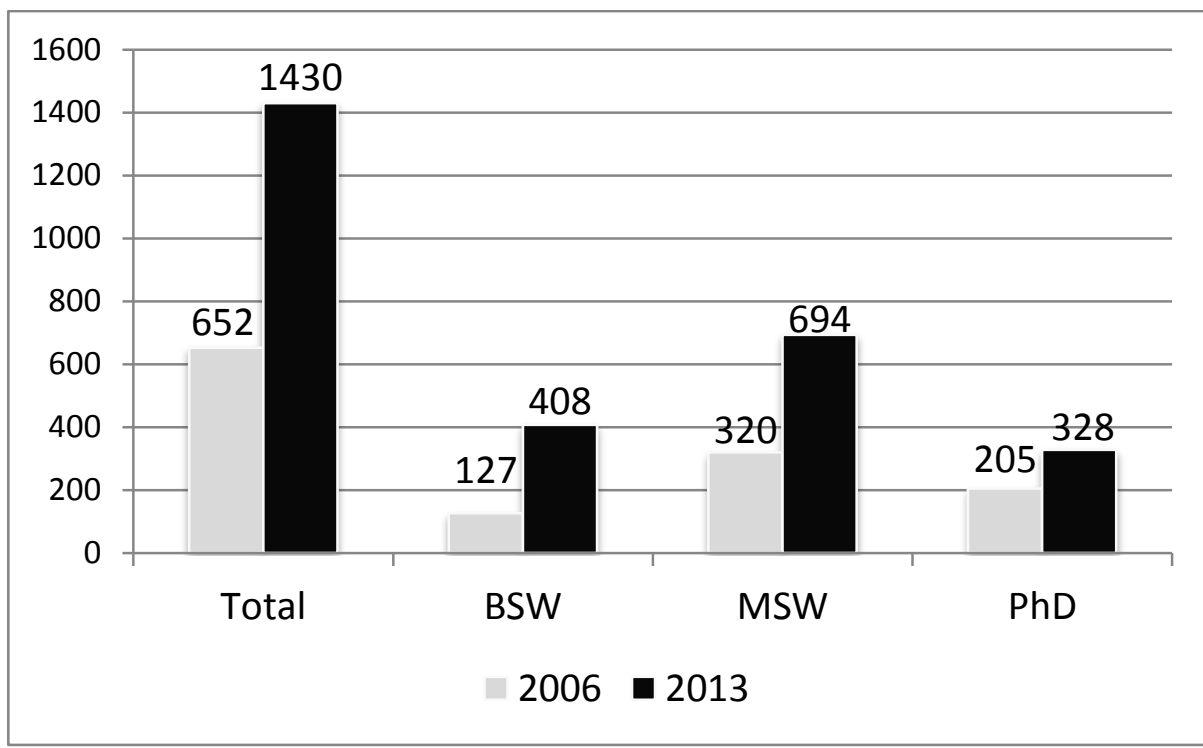

Figure 1: CSWE (2013) Statistics on Social Work Education in the United States: Number of International Social Work Students in the United States, 2006 and 2013. BSW = bachelor of social work; MSW = master of social work; PhD = doctor of philosophy.

International students are defined as "students who have crossed a national or territorial border for the purposes of education and are now enrolled outside their country of origin, carrying student visas for their legal status" (UNESCO Institute for Statistics, 2010, p. 264). International students are distinguished from foreign-born immigrant students who come to the United States with permanent residency or students who were born of foreign parents in the United States and are thus eligible for citizenship. In pursuit of higher education, international students often come to the United States alone, leaving behind their families and friends and accustomed community life styles. As a result, international students generally experience a lack of social support (Bigelow, 2007). This lack of social support can create a significant barrier for international students in their adjustment to American customs and lifestyles and may lead to feelings of homesickness and isolation (Bigelow, 2007; Hendrickson, Rosen, \& Aune, 2011). These difficulties have the potential to interfere with international students' successful attainment of their desired academic goals (Ying \& Han, 2006; Lowinger, He, Lin, \& Chang, 2014). Furthermore, international students in social work face unique challenges in their classrooms and field placements because the profession requires an intimate knowledge of social customs, as well as economic and political policies and systems. Social work curricula is also based on Westernized norms and values, which may be challenging for international social work students particularly those from non-Western cultural backgrounds (Beecher, Eggertsen, Furuto, \& Reeves, 2012; Lough, 2009). Without social support, and in the face of a culture that may differ significantly from their own, strategies for assisting international social work students in their adaptation to the United States in general and to social work education and practice specifically are paramount.

As a structured form of support, this paper proposes a mentoring approach that pairs retired social work professionals with international social work students, arguing this approach may provide a mutually beneficial experience for both. We begin by discussing benefits and challenges that international social work students bring to their classroom and community in the United States. We then describe and discuss the proposed paired-mentoring approach and results of a feasibility survey 
through which respondents were asked to comment on the proposed paired-mentoring approach as well as indicate their desire to participate in a program of the proposed kind. Finally, we discuss implications for social work of the proposed mentoring approach.

\section{Contributions of International Social Work Students}

International social work students receive the benefits of an education in the United States, while in turn making important contributions to their host schools as well as to their larger social environment. For example, students from foreign countries play a pivotal role in increasing the diversity among the student body, which enhances American students' experiences by increasing their exposure to other countries and cultures (Bevis, 2002; Harrison, 2002; Lord, 2011). Particularly in social work international students also enrich the intellectual environment of a school or program by contributing knowledge and skills they bring with them from the fields they represent in their home countries. For example, the CSWE (2015) Educational Policy and Accreditation Standards emphasizes the significance of a global perspective and understanding of human diversity for social work students in training. In social work education, international students facilitate identification and discussion of multicultural perspectives on social welfare problems and policies for both themselves as well as for their fellow students (Rai, 2002). Lindsey (2005) asserted the valuable role played by international social work students for their domestic classmates who are unable to study abroad. By interacting with international students, U.S.-born students gain a broader viewpoint and understanding of global social issues and of the profession of social work as practiced in other countries. Lord (2011) suggests, "our increasing number of international [social work] students [enrich] the classroom and their field internships, offering heightened awareness of the importance of global contexts and human rights, and teaching us about acceptance, respect, openness, and cultural competence through their facility with multiple languages and their abilities to bridge words" (p. 5). Furthermore, international students play a crucial role in recruiting other international social work students and in developing global professional networks (Rai, 2002). In fact, based on the benefits contributed by international students, many social work programs are focusing deliberate recruitment efforts using a global network of schools and social welfare organizations, conferences, and advertisements in foreign journals (Rai, 2002; Verbik \& Lasanowski, 2007).

\section{Challenges Facing International Social Work Students}

Despite the numerous contributions made by international students, Verbik and Lasanowski (2007) point out that once these international students enter American institutions of higher education, little attention is paid to supporting them during their adjustment to American culture. Existing literature suggests a number of challenges facing international social work students as they adapt to their new lives in the United States. The challenges facing these students include language comprehension, loneliness/homesickness, a lack of social networking, cultural barriers, different learning styles, Westernized pedagogies, and financial difficulties (Cree, 2012; Lough, 2009; Irizarry \& Marlowe, 2010).

\section{Language Comprehension}

English proficiency is a significant factor in the adjustment and academic success of international students (Poyrazli, Arbona, Nora, McPherson, \& Pisecco, 2002; Poyrazli, Kavanaugh, Baker, \& AlTimimi, 2004). Any lack of proficiency in English among international students from non-Englishspeaking countries negatively impacts necessary classroom skills, such as writing, critical thinking, 
and discussion skills (Andrade, 2006; Hellsten \& Prescott, 2004). Hellsten and Prescott's (2004) study finds the lack of English proficiency prevents international students from participating in classroom discussion and collaborative study, speaking in public, and making American friends. Considering the fact that many social work courses are composed not only of lecture, but also of group discussion, role-play, debate, presentation, and case study, international social work students from non-English-speaking countries may be more likely to face language barriers. Language comprehension also affects socialization. International students from non-English-speaking countries have been found to spend less time relaxing and socializing, as they put greater effort and time into preparing for their classes and overcoming their academic challenges (Dipeolu, Kang, \& Cooper, 2007). In fact, Chun and Poole (2009) surveyed 51 graduate-level Korean social work students at 16 social work programs to identify the major stressors they felt they faced. Academic pressure was the greatest source of stress experienced by these Korean social work students followed by financial stress, and cultural barriers.

\section{Challenges in Classroom and Field Placements}

International social work students not only face unique problems in their classrooms but in their field placements as well. Social science and humanities majors, such as social work, require international students to have the capacity to understand and interpret the host country's historical, cultural, political, and social context (Hanassab \& Tidwell, 2002; Zhou, Knoke, \& Sakamoto, 2005). International students are thus more likely to struggle than domestic students due to the lack of background experience or knowledge, which may result in a low sense of content mastery. Furthermore, social work curriculum based on Westernized values and norms presents additional challenges to international students from non-Western cultural backgrounds (Beecher et al., 2012; Lough, 2009). The social work curriculum in the United States is designed to train students to "serve the needs of local populations in their countries of origin" (Lough, 2009, p. 793). Therefore, social work pedagogy and practices are based on Westernized value and norms, such as individualism (Beecher et al., 2012; Graham, 2002; Lough, 2009). According to Lough (2009), international social work students report "[social work] curriculum is strongly focused on U.S.-dominant values and policies" (p. 795). In a qualitative study of 15 international social work students, Lough (2009) went on to report their concern that some of the knowledge and skills taught in the United States are inappropriate to apply in their home countries, though students acknowledged their appreciation of the opportunities to be introduced to issues facing underrepresented populations, such as individuals with disabilities and lesbian, gay, bisexual, and transgender populations, and to acquire critical thinking skills (Lough, 2009).

Another classroom challenge faced by international social work students includes culturally different learning/teaching styles. Instructors indicate major concerns over international students' passive attitudes toward participating in classroom activities (Brydon, 2012; Hellsten \& Prescott, 2004; Wong, 2004). This reported passivity on the part of international students may be explained partially by international students' language barriers, yet it is also closely associated with students' different learning styles and cultural backgrounds (Hellsten \& Prescott, 2004). For example, students from Asian countries based on Confucian values, such as China, Korea, Japan, and Taiwan, are more familiar with teacher-driven learning styles and are "reluctant to 'stand out' by expressing their views or raising questions" (Johnston, Koshiyama, Ries, \& Rush, 2013, p. 84). Many of these students are educated to accept the authority of teachers, keep formal and distant relationships with them, and give correct answers (Brydon, 2012; Markus \& Kitayama, 1991). Due to this difference in perspective regarding the role of authority and the power differential between students and 
instructors, international students may have greater difficulty interacting with teachers or other faculty members when compared with their domestic student counterparts (Zhao, Kuh, \& Carini, 2005). In addition, studies suggest international students, particularly from non-Western countries, are generally less likely to be familiar with small group classes, seminars, and interactive learning processes. Thus, international students are challenged when adjusting to American teaching/learning styles, particularly in the social work classroom where these are the preferred approaches to pedagogy (Felix \& Lawson 1994; Irizarry \& Marlowe, 2010; Samuelowicz, 1987). Samuelowicz (1987) insists on the importance of helping international students change "from passive reception of authoritarian teaching to self-developing, self-motivated, critical learning where critical and analytic thinking is more important that reproducing ideas" (p. 124). More recently, Irizarry and Marlowe (2010) stresses that some bridging is required to help international social work students to become "independent learners" and to "understand what is expected of them and how they can access support in a different educational and social context" (p. 99).

International social work students also experience difficulties related to field practice. Zunz and Oil (2009) report that international MSW students in rural areas struggled with finding agencies appropriate for them and with accessing transportation to and from their field placements. In their study, international social work students reported being challenged by cultural and linguistic difficulties in their field placements. International students have also reported feeling excluded from field tasks requiring sophisticated communication skills, resulting in a more limited field placement experience than those had by their domestic student counterparts in social work (Zunz \& Oil, 2009).

\section{Lack of Social Capital and Emotional Difficulties}

Because many international students arrive in the United States without family and friends, their high stress, homesickness, and feelings of isolation are additional challenges (Cree, 2012; Irizarry \& Marlowe, 2010; Rajapaksa \& Dundes, 2002). Social capital theory is appropriate to understand these various emotional difficulties. Portes (1998) defines social capital as an ability to secure resources by virtue of membership in social networks or larger social structures. That is, social capital theory emphasizes relationships and social networking. Putnam (1995) introduces the concept of "bridging social capital" that is referred to as social networking with people who have different backgrounds (e.g., race, ethnicity, gender, social status, and religion). In fact, Zhou and Bankston (1994) applied the theory to explain the adaptation experiences of Vietnamese immigrant youth in the United States. They argue the lack of social networking and the lack of a sense of belonging in the new host country hinder many international students from adjusting successfully to American schools and achieving their desired academic goals.

Sawir, Marginson, Deumert, Nyland, and Ramia (2008) have asserted international students experience three kinds of loneliness: "personal loneliness because of the loss of contact with families and friends; social loneliness because of the lack of social networks; and cultural loneliness, triggered by the absence of the preferred cultural and/or language environment" (p. 1). According to recent studies (Lee \& Rice, 2007; Wilton \& Constantine, 2003), international students from Latin American and Asian countries experience greater levels of stress and exhibit greater emotional problems than students from Western Europe, Canada, and Australia due to language and cultural challenges. Building social capital may play a pivotal role in easing these challenges for international students, thus reducing homesickness and loneliness (Portes, 1998). For example, Andrade (2006) has found loneliness and homesickness to be largely affected by international students' sense of satisfaction with their interpersonal relationships with Americans. In other words, the more interaction international students had with domestic people and American culture, the more fulfilling their 
experience, and the better their adjustment to their life and their host schools in the United States. Hendrickson et al. (2011) have found that international students with a higher ratio of American acquaintances reported significantly higher levels of life satisfaction, contentment, and significantly lower levels of homesickness. For example, international students who have few close American friends missed opportunities to experience traditional American cultural rituals, such as the Thanksgiving dinner, increasing feelings of social isolation (Andrade, 2006).

Addressing this issue of social capital or friendship, Sherry, Thomas, and Chui (2010) conducted an online survey of 121 international students across the United States. Some international students from Asian countries mentioned that developing relationships with people outside of their school environment made them feel more connected to American society in general. However, Sherry et al. (2010) report 50\% of their respondents indicated their friends were limited to other international students. While $15 \%$ reported they had made new friends, these friendships were with others from their homeland, $10 \%$ of respondents reported they had no friends (domestic or international) in the United States. Thus, international students, particularly those from non-English-speaking countries, have little social capital due to the challenges they experience in building new relationships.

\section{Financial Difficulties}

Colleges and universities in the United States have some of the highest tuition rates among the 34 Organization for Economic Co-Operation and Development member countries, and these costs rise annually, sometimes dramatically. For example, after adjusting for increases in the Consumer Price Index, tuition and fees paid for a public 4-year university or college in 2012-2013 was 3.57 times higher than it was in 1982-1983 (College Board, 2012). Because the visas provided to international students require them to attend school full-time and do not permit them to work off-campus, these students often experience financial hardship. Moreover, financial aid and scholarship money are primarily limited to domestic students or permanent residents, making it unavailable to international students. Thus, many international students have to depend on personal or family resources to finance their tuition, as well as their living costs. According to the Institute of International Education (2014), about 65\% of international students received financial backing from personal or family sources with about $8 \%$ receiving assistance to study in the United States from their home country government, organizations, or universities. Finances challenge international students socially as well as emotionally and are often cited as a reason to discontinue their studies in the United States.

\section{Lack of Support for International Social Work Students}

Despite the challenges facing international social work students (particularly those from nonEnglish-speaking countries) and ample literature highlighting the importance of social networks and supports, currently insufficient services exist for these students. Academic advisors would be a likely resource with whom international students could address the challenges they face, but many advisors report a lack of sufficient time and resources to engage in these activities (Chowa, Danso, \& Sherraden, 2007; Cree, 2012; Milem, Berger, \& Dey, 2000). In addition, a survey of 20 social work programs reported that existing support services for international social work students were offered by their college or university resources rather than by the social work department itself (Alexander \& Bozeman, 2007). Of available services for international students, most were related to administrative tasks such as visa documents and housing information, rather than social support. Cree (2012) found schools seem to leave support functions for international social work students to peers or to other university services, such as counseling. Though some schools have established 
language support services, such as writing centers, English-language courses, and tutoring, only a few international students were able to take advantage of these resources due to either limited service availability, costs, or both. According to Chun and Poole's (2009) study, Korean social work students studying in United States used prayer as their major coping strategy to address social and emotional stressors. They had also indicated needs for social support as a way to address their identified social stressors as they initially adapted to their lives in the United States. Thus, the authors suggest social work programs should provide better access to social support services to help international students cope successfully with the stressors they face in the United States, generally as well as in their school environment specifically.

\section{Paired-Mentoring Approaches}

Based on the literature discussed above as well as on author's experiences, this paper proposes a mentoring program designed to provide international social work students with social support in order to assist in their acculturation to the United States. Supported by the work of Irizarry and Marlowe (2010), which stressed social support for international social work students, the proposed mentoring program would pair retired social work professionals with international social work students. While no existing empirical work examines the impact of this proposed paired-mentoring approach, a number of studies suggest powerful and effective results of mentoring with underrepresented populations.

Mentoring is a structured form of social support aimed at empowering those who feel vulnerable through the vehicle of a personal relationship (National Mentoring Partnership, 2005). According to Hamilton and Darling (1996), mentors provide social and emotional support, access to diverse networks, and necessary information and resources to their mentees. The existing literature on mentoring demonstrates a range of benefits accrued to domestic college students who have been paired with mentors. For example, Campbell and Campbell (2007) examined the effects of a faculty/student mentoring program for racial/ethnic minority college students. They compared a group of 339 students assigned to mentors with a control group of 339 students without mentors. The study found that mentored college students have shown statistically significantly higher grade point averages and retention rates when compared with their nonmentored peers. In addition, mentored students were more likely to attend graduate school or pursue teaching credentials than their nonmentored counterparts. Interviewing 112 first-year Latino/Latina college students from a large public university, Bordes and Arredondo (2007) have also found a university-based mentoring experience having had a positive influence on students' perceived comfort in their university environment and on retention rates. The results further suggest that enhanced feelings of comfort experienced by students were largely influenced by levels of cultural congruity and feelings of belonging, which increased through the mentoring experience. Moreover, a study conducted by Laura, Stephen, and Talya (2006) have found a positive association between mentoring programs and doctoral students' self-efficacy, after controlling for the students' initial academic ability and previous self-efficacy. Newman (2000) further demonstrated mentoring programs affect students' academic motivation and play a crucial role in dealing with problems and avoiding loneliness. Hence, the results of these studies suggest mentoring programs provide mentees with opportunities for exposure to people different from themselves, access to information and resources, increased selfconfidence and self-esteem, as well as the development of social skills. However, no studies have yet been conducted to examine the potential benefits of mentoring programs for international social work students, especially those paired in a paired-mentor program as we describe. 
Song \& Petracchi, 2015

\section{Mentor and Mentee Recruitment}

A growing body of literature suggests that the mentor's capability, in terms of intervention skills, knowledge, and cultural sensitivity, is critical in determining the success of the mentoring program (Clutterbuck \& Lane, 2004; Grant-Thompson \& Atkinson, 1997; Park-Saltzman, Wada, \& Mogami, 2012). We propose retired social work professionals to be ideal mentors. Retired social work professionals have time as well as insight from their careers to support international social work students in their transition to their education and to their day-to-day life in the United States. Furthermore, a retired social worker's practical and professional knowledge may promote academic as well as field success for international social work students. Though currently employed social workers who possess a desire to assist international students would be eligible to serve as mentors, our proposed approach focuses on retired social workers because with retirement comes freedom from day-to-day work schedules, thus providing the time needed to commit to the mentor/mentee relationship.

In our proposed approach, mentors would be recruited from alumnae of an existing social work program, retired faculty, and retired social workers. For example, the Shared Interest Groups of the National Association of Social Workers (NASW) provides recruiting opportunities for retired social workers. The Shared Interest Group has been used for other recruitment projects such as the Illinois Chapter of NASW seeking retired social workers to provide networking and work/volunteer opportunities (NASW, 2015). In our proposed approach, to be selected as a mentor, the social worker would agree to meet regularly with their international social work student mentee, thus encouraging the development of supportive social relationships suggested as necessary by the existing literature.

To recruit participating international students, social work programs would advertise the opportunity to instructors and matriculating international students via email perhaps even including a link to the mentoring program within the school website. Hanging posters on classroom bulletin boards or in common areas is another strategy for recruiting mentees who might self-select to participate in the program. Both mentors and mentees would voluntarily select to participate in the program. In fact, in our proposed program involuntary participation is discouraged to limit further stress on the international student. The proposed pairing between social workers and international social work students is anticipated to provide an important bridge to experience new cultures for both mentors and mentees, including exposure to language, foods, people, and resources thus, in our proposed approach, the mentor/mentee pair would ideally be cross-cultural. To maximize the effects of the mentoring program, nonhierarchical relationships are also seen as crucial, created by both parties respecting one another's culture (Hansman, 2002). This nonhierarchical relationship with their elder mentors could be a valuable experience for international social work students to learn ways to build relationships and would be an area addressed with mentors in advance of the initial meeting between mentor and mentee.

\section{Goals and Objectives}

The goal of the proposed mentoring program is to provide international students, particularly those with non-Western backgrounds, with a means for positive social support during their period of transition to the United States. Based on findings from the review of contemporary literature, the proposed mentoring program also has a number of objectives. For international social work students, the proposed paired-mentoring program provides an opportunity to establish a personal relationship with a local social work professional (networking), become familiar with American life through social and emotionally supportive interactions and experiences, and provide information and resources to 
improve academic performance. For social work professionals, the program provides an opportunity to share their expertise and life experiences through assisting international students and have a global experience without leaving the United States.

\section{Procedure of the Mentoring Program}

Prior to meeting with their mentees, potential mentors would be asked to participate in an orientation with multicultural training led by school staff or faculty members in charge of the mentoring programs. This orientation would allow mentors to have a chance to recognize their own cultural values and potential biases, which may help them understand the values held by their mentees and facilitate a nonjudgmental attitude about these values. This orientation would also allow mentors to understand the goals of the paired-mentoring program and gain necessary skills and information, such as creating a safe climate, developing a trusting nonhierarchical relationship, learning about mentoring ethics, and obtaining the basic background of international students in social work. We propose mentors and mentees commit to regular meetings at least monthly, preferably once a week. For the first month of the program, we recommend mentors meet their mentees at the social work program as a group. These initial meetings aim to build comfort and a trusting relationship between the mentors and their mentees perhaps with the social work program committing a faculty member of coordinate the mentor/mentee relationships and activities. Following the initial meeting, students and their mentors determine how often they will meet and what they will do together. We envision a variety of organized mentoring activities for these meetings, such as helping with English (with mentees for whom conversational English is a challenge), discussing social issues, participating in various community events, and serving traditional foods. As with any social work intervention, we suggest the mentoring program be evaluated by the social work coordinator using surveys and in-depth interviews of both mentors and mentees. Through the evaluations, the effectiveness of the mentoring program can be measured.

\section{A Voluntary Feasibility Survey of the Proposed Mentoring Approach}

While our proposed mentor-mentee approach has evolved from the literature as well as from personal experience, we wanted to obtain input from international students regarding their impressions of our proposal. We also were interested in the perspective of the proposed approach from retired social workers. Therefore, we piloted a short survey during the 2012-2013 academic year at a large urban university to identify the extent to which both international social work students and retired social work professionals would be willing to participate in the proposed pairedmentoring program. Assessing the feasibility of the approach to address the needs of international social work students was another goal of the survey.

This university's School of Social Work houses a combined accredited baccalaureate and master's programs as well as a doctoral program. International students in all three of the school's programs were approached to participate in this survey. The survey was conducted at an annual luncheon meeting for all international social work students organized by the School of Social Work. At the meeting, international students were invited by a fellow student to participate in the self-report survey though there was no pressure to do so (no faculty were involved in asking students to complete the survey). To make participants feel comfortable, the survey was administered by a trained doctoral student. Participation was voluntary and no identifying information was provided on submitted surveys. International students were simply asked if they wished to provide information anonymously, and then asked to return their completed survey to a sealed box to ensure confidentiality. 
At the annual alumni meeting, retired social workers who had an historic affiliation with the school were also offered the opportunity to complete surveys anonymously. Through structured questions, the survey queried these professionals regarding the proposed paired-mentoring approach.

\section{Results}

Thirty-one currently enrolled international social work students at this school responded to the survey. Table 1 presents the demographic characteristics of these international students and their assessment of the paired-mentoring approach. Not surprisingly, a majority of sample students were female (84\%). Forty-two percent were from China with another $42 \%$ from South Korea. Students from Vietnam, Mexico, Haiti, Chile, and Singapore were also included. Among the respondents, 65\% were MSW students and 35\% were doctor of philosophy (PhD) students. No bachelor of social work students responded. The mean age of MSW students was 26.2 years $(S D=3.22)$ and that of $\mathrm{PhD}$ students was 32.7 years $(S D=4.69)$. On average, the participants had three American friends $(M=$ $3.43, S D=2.93$ ), but $20 \%$ of all international social work students reported that they had no American friends.

Results of the survey found that nearly all international students who participated favored a pairedmentoring program as described. Specifically, all participants thought they could benefit from such an approach. All MSW students and $64 \%$ of the PhD students indicated their desire to actually participate in the paired-mentoring program with a retired social worker. Two doctoral students had no intention of participating in the proposed paired-mentoring program indicating lack of time as their major reason. Another two doctoral students indicated they were unsure of their feelings about the proposed program.

Table 1: Characteristics of the Sample International Social Work Students ( $\mathrm{N}=31$ )

\begin{tabular}{|c|c|c|}
\hline & $\begin{array}{l}\text { MSW }(n=20) \\
\% \text { or } M(S D)\end{array}$ & $\begin{array}{l}\text { PhD }(n=11) \\
\% \text { or } M(S D)\end{array}$ \\
\hline \multicolumn{3}{|l|}{ Nationality } \\
\hline China & 60 & 9 \\
\hline South Korea & 20 & 82 \\
\hline Other & 20 & 9 \\
\hline Female & 90 & 73 \\
\hline Age & $26.2(3.2)$ & $32.7(4.7)$ \\
\hline Number of American friends & $3.4(3.1)$ & $3.5(4.7)$ \\
\hline In America for less than 2 years & 70 & 21 \\
\hline \multicolumn{3}{|l|}{ Paired-mentoring program } \\
\hline $\begin{array}{l}\text { Having a mentor while studying in America is } \\
\text { important. }\end{array}$ & 95 & 100 \\
\hline $\begin{array}{l}\text { Finding an American mentor on your own is } \\
\text { difficult. }\end{array}$ & 94 & 89 \\
\hline $\begin{array}{l}\text { It will benefit international social work } \\
\text { students. }\end{array}$ & 100 & 100 \\
\hline $\begin{array}{l}\text { I am willing to participate in this proposed } \\
\text { mentoring program. }\end{array}$ & 100 & 64 \\
\hline
\end{tabular}

Note. $\mathrm{MSW}=$ master of social work; $\mathrm{PhD}=$ doctor of philosophy. 
With respect to the responses from professional social workers, $32 \%$ were retired. Eighty-four percent of all professionals felt a paired-mentoring approach would benefit international students, while $90 \%$ indicated they would benefit from the experience as well. All retired respondents indicated their willingness to participate actively in a paired-mentoring program with international social work students at the school. Ninety-two percent of respondents who were not yet retired also reported their willingness to serve as a mentor for international students after their retirement. A professional mental health therapist expressed his or her desire to serve as a mentor for international students even before retirement.

In summary, all international social work students who responded to this voluntary survey felt the proposed paired-mentoring program would benefit them. Further, all MSW students and two thirds of the $\mathrm{PhD}$ students as well as all professional social workers underscored their willingness to participate in the program if it were made available to them.

\section{Discussion}

There are several limitations to this pilot study. First, the sample size for both students and professionals was small, and not all participating professionals were retired. In addition, because the data was collected from a university in an urban area, the findings of this study cannot be generalized to all international social work students in the United States. Despite the fact that results are derived from a small convenience sample, the findings of this study could be used as a foundation to create paired-mentoring programs with positive implications for social work educators working with international students, as well as researchers interested in the challenges facing these students. This feasibility study suggests the paired-mentoring approach has the potential to improve international social work students' transition to their education and lives in the United States. The supportive relationships and regular meetings with mentors could provide positive social experiences and facilitate English proficiency, as well as provide knowledge about the United States that would benefit international students both inside and outside of the classroom. In particular, the findings suggest international MSW students feel more of a need for the proposed mentoring program than international $\mathrm{PhD}$ students. This difference might be attributed to the length of stay in the United States between MSW and PhD students. While more than $70 \%$ of MSW students in this study have lived in the United States less than 2 years, only $21 \%$ of $\mathrm{PhD}$ students have done so.

This proposed paired-mentoring program may provide an opportunity for retired social workers to engage in a meaningful activity, which acknowledges their plentiful professional knowledge developed through a lifetime of experience. Cross-cultural matching may also benefit both the mentor and mentee by exposing them to the subtleties of cultural difference and challenging cultural assumptions (Cohen, Garcia, Apfel, \& Master, 2006). International students' ability to interact effectively with their mentors who have different backgrounds may help them work more effectively in field settings. Hence, the paired-mentoring approach may enhance the well-being of both the international social work students as well as the retired social workers. Ultimately, this approach has the potential to create a better academic environment for the entire social work program in the United States by encouraging greater sensitivity to and understanding of issues of international cultural diversity. The next step in testing the paired-mentoring approach would be a pilot study, with an experimental design for full and in-depth assessment of both student-mentee and mentor experiences. 
Song \& Petracchi, 2015

\section{Conclusion}

International students are a rapidly growing population of students in colleges and universities across the United States. Although international social work students play a crucial role in enhancing the diversity of their schools, they are also a vulnerable population. Existing research has documented insufficient support for these students as they transition both academically and socially into American culture. As mentioned earlier, lack of social capital is a serious problem facing international social work students in adjusting socially as well as achieving desired academic outcomes.

Our interest is in assisting international social work students in their social transition in order to facilitate positively their experiences in the United States as they complete their social work education. In order to do so, this paper has proposed a paired-mentoring program between international social work students and retired social workers. A feasibility study of the proposed approach found both students and social workers in support of the idea and willing to participate. Networking among and between domestic social work students and international students, facilitated by retired social workers has the potential to improve the life experiences of all involved. As we have found in the social work field practicum, some of the most meaningful and long lasting learning is not found in our brick-and-mortar classrooms but in a larger context. Creating a community for international social work students will likely continue to bear this out.

\section{References}

Andrade, M. S. (2006). International students in English-speaking universities: Adjustment factors. Journal of Research in International Education, 5, 131-154.

Alexander, P., \& Bozeman, L. (2007). The relevance of international students in U.S. schools of social work. Paper presented at International Social Work Conference, Boston, MA.

Beecher, B., Eggertsen, L., Furuto, S., \& Reeves, J. (2012). International student views of social work in select Asian and Pacific island countries. Social Work Education, 31, 435-450.

Bevis, T. B. (2002). At a glance: International students in the United States. International Educator, $11,12-17$.

Bigelow, M. H. (2007). Social and cultural capital at school: The case of a Somali teenage girl. In N. R. Faux (Ed.), Low-educated adult second language and literacy acquisition proceedings of symposium (pp. 7-22). Richmond, VA: Literacy Institute at Virginia Commonwealth University.

Bordes, V., \& Arredondo, P. (2007). Mentoring and 1st-year Latina/o college students. Journal of Hispanic Higher Education, 4, 114-133.

Brydon, K. (2012). Promoting diversity or confirming hegemony? In search of new insights for social work. International Social Work, 55, 155-167.

Campbell, T. A., \& Campbell, D. E. (2007). Outcomes of mentoring at-risk college students: Gender and ethnic matching effects. Mentoring \& Tutoring, 15, 135-148.

Chowa, G., Danso, K., \& Sherraden, M. (2007). Under-utilized contributions by international students (CSD Working Papers No. 07-20). St. Louis, MO: Washington University in St. Louis. 
Chun, J., \& Poole, D. (2009). Conceptualizing stress and coping strategies of Korean social work students in the U.S.: A concept mapping application. Journal of Teaching in Social Work, 29, $1-17$

Clutterbuck, D., \& Lane, G. (2004). The situational mentor: An international review of competences and capabilities in mentoring. Aldershot, United Kingdom: Gower Publishing Limited.

Cohen, G. L., Garcia, J., Apfel, N., \& Master, A. (2006). Reducing the racial achievement gap: A social-psychological intervention. Science, 313, 1307-1310.

College Board. (2012). Trends in college pricing 2012. Retrieved from http://www.councilofpresidents.org/docs/r_d_docs/college-pricing-2012-full-report_0.pdf

Council on Social Work Education (CSWE). (2013). Statistics on social work education in the United States. Retrieved from http://www.cswe.org/File.aspx?id=74478

Council on Social Work Education (CSWE). (2015). Educational policy and accreditation standards. Retrieved from http://www.cswe.org/File.aspx?id=81660

Cree, V. E. (2012). I'd like to call you my mother: Reflections on supervising international PhD students in social work. Social Work Education, 31, 451-464.

Dipeolu, A., Kang, J., \& Cooper, C. (2007). Support group for international students: A counseling center's experience. Journal of College Student Psychotherapy, 22, 63-74.

Felix, U., \& Lawson, M. (1994). Evaluation of an integrated bridging course on academic writing for overseas postgraduate students. Higher Education Research and Development, 13, 59-69.

Graham, M. (2002) Creating spaces: exploring the role of cultural knowledge as source of empowerment in models of social welfare in black communities. British Journal of Social Work, 32, 35-49.

Grant-Thompson, S. K., \& Atkinson, D.R. (1997). Cross-cultural mentor effectiveness and African American male students, Journal of Black Psychology, 120-134, doi:10.1177/00957984970232003

Hanassab, S., \& Tidwell, R. (2002). International students in higher education: Identification of needs and implications for policy and practice. Journal of Studies in International Education, $6,305-322$.

Hamilton, S. F., \& Darling, N. (1996). Mentors in adolescents' lives. In K. Hurrelmann \& S. F. Hamilton (Eds.), Social problems and social contexts in adolescence: Perspectives across boundaries (pp. 199-215). Hawthorne, NJ: Aldine de Gruyter.

Hansman, C. A. (2002). Critical perspectives on mentoring: Trends and issues (Information Series No. 388). Columbus, OH: ERIC Clearinghouse on Adult, Career, and Vocational Education.

Harrison, P. (2002). Educational exchange for international understanding. International Educator, $11,2-4$.

Hellsten, M., \& Prescott, A. (2004) Learning at university: The international student experience. International Education Journal, 5, 344-351.

Hendrickson, B. Rosen, D., and Aune, R. K. (2011). An analysis of friendship networks, social connectness, homesickness, and satisfaction levels of international students. International Journal of Intercultural Relations, 35, 281-295. 
Institute of International Education. (2010). Open doors 2010. Retrieved from http://www.iie.org/Who-We-Are/News-and-Events/Press-Center/Press-Releases/2010/201011-15-Open-Doors-International-Students-In-The-US

Institute of International Education. (2014). Open doors 2014: Report on international educational exchange. Retrieved from http://www.iie.org/Research-and-Publications/Open-Doors

Irizarry, C., \& Marlowe, J. (2010). Beyond mere presence: Making diversity work. Social Work Education, 29, 96-107.

Johnston, C., Koshiyama, Y., Ries, T., \& Rush, T. (2013). Learner autonomy in East Asian university contexts. Journal of Educational and Social Research, 3, 83-89.

Lee, J. J., \& Rice, C. (2007). Welcome to American? International student perceptions of discrimination. Higher Education, 53, 381-409.

Lindsey, E. W. (2005). Study abroad and values development in social work students, Journal of Social Work Education, 41, 229-249.

Lord, S. (2011). Lessons from our students: Unsung heroes in a time of global relational warming. International Social Work, 55, 29-39.

Lough, B. J. (2009). Curricular blueprinting: The relevance of American social work education for international students. Social work education, 28, 792-802.

Lowinger, R., He, Z., Lin, M., \& Chang, M. (2014). The impact of academic self-efficacy, acculturation difficulties, and language abilities on procrastination behavior in Chinese international students. College Student Journal, 48, 141-152.

Markus, H. R., \& Kitayama, S. (1991). Culture and the self: Implications for cognition, emotion, and motivation. Psychological Review, 98, 224-253.

Milem, J. F., Berger, J. B., \& Dey, E. L. (2000). Faculty time allocation: A study of change over 20 years. Journal of Higher Education, 71, 454-475.

National Association of Social Workers (NASW). (2015). Retired social workers SIG. Retrieved from http://www.naswil.org/naswil/sigs/retired-social-worker-sig/

National Mentoring Partnership. (2005). How to build a successful mentoring program using the elements of effective practice. Retrieved from http://www.mentoring.org/about_mentor

Newman, R. S. (2000). Social influences on the development of children's adaptive help seeking: The role of parents, teachers, and peers. Developmental Review, 20, 350-404.

Laura, P., Stephen, G., \& Talya, B. (2006). Does advisor mentoring add value? A longitudinal study of mentoring and doctoral student outcomes. Research in Higher Education, 47, 451-476.

Park-Saltzman, J., Wada, K., \& Mogami, T. (2012). Culturally sensitive mentoring for Asian international students in counseling psychology. The Counseling Psychologist, 40, 895-915. doi:10.1177/0011000011429831

Portes, A. (1998). Social capital: Its origins and applications in modern sociology. Annual Review of Sociology, 24, 1-24.

Poyrazli, S., Arbona, C., Nora, A., McPherson, R., \& Pisecco, S. (2002). Relation between assertiveness, academic self-efficacy, and psychosocial adjustment among international graduate students. Journal of College Student Development, 43, 632-642. 
Poyrazli, S., Kavanaugh, P., Baker, A., \& Al-Timimi, N. (2004). Social support and demographic correlates of acculturative stress in international students, Journal of College Counseling, 7, $73-82$.

Rai, G. (2002). Meeting the educational needs of international students: A perspective from U.S. schools. International Social Work, 45, 2-33.

Rajapaksa, S., \& Dundes, L. (2002). It's a long way home: International student adjustment to living in the United States. College Student Retention 4, 15-28.

Samuelowicz, K. (1987). Learning problems of overseas students: Two sides of a story. Higher Education Research and Development, 6, 121-133.

Sawir, E., Marginson, S., Deumert, A., Nyland, C., \& Ramia, G., (2008). Loneliness and international students: An Australian study. Journal of Studies in International Education, 12, 148-180. doi:10.1177/1028315307299699

Sherry, M., Thomas, P., \& Chui W. H. (2010). International students: A vulnerable student population. High Education, 60, 33-46.

UNESCO Institute for Statistics. (2010). Global education digest 2010. Montreal, Canada: Author.

Verbik, L., \& Lasanowski, V. (2007). International student mobility: Patterns and trends. London, United Kingdom: Observatory of Borderless Higher Education.

Wilton, L., \& Constantine, M. G. (2003). Length of residence, cultural adjustment difficulties, and psychological distress symptoms in Asian and Latin American international college students. Journal of College Counseling, 6, 177-186.

Wong, J. K. (2004). Are the learning styles of Asian international students culturally or contextually based? International Education Journal, 4, 154-166.

Ying, Y., \& Han, M. (2006). The contribution of personality, acculturative stressors, and social affiliation to adjustment: A longitudinal study of Taiwanese students in the United States. International Journal of Intercultural Relations, 30, 623-635.

Zhao, C., Kuh, G. D., \& Carini, R. M. (2005). A comparison of international student and American student engagement in effective educational practices. Journal of Higher Education, 76, 209231.

Zhou, M., \& Bankston, C. L. (1994). Social capital and the adaptation of Vietnamese youth in New Orleans. International Migration Review, 28, 821-845.

Zhou, Y. R., Knoke, D., \& Sakamoto, I. (2005). Rethinking silence in the classroom: Chinese students' experiences of sharing indigenous knowledge. International Journal of Inclusive Education, 9, 287-311.

Zunz, S. J., \& Oil, K. R. (2009). A preliminary look at international students in MSW filed placements at nonurban U.S. campuses. Journal of Social Work Education, 45, 131-137. 
The Journal of Social Work in the Global Community, sponsored by Walden University, is a scholarly peer-reviewed journal that promotes research in the practice of international social work with a focus on social change. JSWGC publishes high-level research, literature and book reviews, and thought pieces related to the field of social work practice and social change in our global community.

Walden University Publishing: http://www.publishing.waldenu.edu 